\title{
Re-revisiting the Mass Privatisation - Mortality Debate : a response to Stuckler, King and Mckee
}

\author{
Christopher J Gerry* \\ * UCL School of Slavonic and East European Studies \\ c.gerry@ucl.ac.uk
}

\begin{abstract}
David Stuckler, Lawrence King and Martin McKee (IN THIS ISSUE) (hereafter, SKM) are unhappy that their bold claims that rapid mass privatisation was an important cause of postcommunist mortality fluctuations have been disputed. In defending their claims, SKM variously accuse those questioning them of statistical manipulation and obscurantism, ideological bias, conflicts of interest, misrepresentation, denialism (e.g. as in climate change denial) and data torture. These are uncomfortable associations for any researcher. So, let me be clear, no one is denying the occurrence of unprecedented spikes in mortality and morbidity in the early 1990s across parts of the post-communist world; what is being questioned is the assertion that rapid mass privatisation was "a crucial determinant of differences in adult mortality trends". This claim, stemming from a cross-national analysis covering 24 countries for up to 14 years, hardly merits association with the vast body of impressive scientific theory and evidence underpinning the link between environmental damage and climate change.

Nevertheless, the discussion is important because it goes to the heart of what, when and how much can be claimed from small scale, cross-national data analysis. While SKM have raised an interesting question, their claims are far louder and bolder than the data justify and there are lessons, for social scientists and epidemiologists, that can be drawn from this. Moreover, their claim that it is wrong for their critics to explore their findings without putting forward and testing alternative hypotheses is anti-scientific (Popper, p.39, 1959): falsifiability defines the scientific endeavour.
\end{abstract}

In their response to my article (Gerry, IN THIS ISSUE) SKM state that I am part of a game of "statistical obscurantism". They advance this allegation in four stages by: (i) revisiting the key facts and concepts; (ii) repeating discussion of the methodological challenges; (iii) comparing Russia (a mass privatiser) with Belarus (not a mass privatiser); and (iv) providing a set of regressions which they claim demonstrate "data torture". I will take these in turn.

\section{Key facts / concepts}

The key facts presented are not, and never have been, in dispute. In presenting them, however, SKM achieve two things. First, their apparent misunderstandings highlight key conceptual differences in our respective approaches. Second, they undermine their own authority by radically misrepresenting and/or misusing much of the literature they cite in their 'key facts' section. In particular they misrepresent: (i) Brainerd (1998, 2001), claiming that she invoked rapid mass privatisation using quantitative methods, when in fact she made no tests relating to mass privatisation and actually argued that rapid reformers avoided the worst of the crisis; (ii) Saburova et al. (2011), who in fact provide compelling support for the persistence hypothesis: "longer and more frequent zapois were an indication of loss of control, increasing problem drinking and were accompanied by a gradual decline in health status", continuing that the explanation lies in workplace drinking patterns that "extend well back into the Soviet period" (p.5); (iii) Gerry et al. (2010), stating that they invoke pollution 
as a possible cause of persistence in the post-communist case. They do no such thing, instead making reference to pollution purely to illustrate a generic concept.

SKM insist that my contention that health states are persistent and evolve gradually over time is "biologically implausible". This insistence is at odds with established approaches in both epidemiology and the social sciences. In the former, there is a rich seam of life-course literature (e.g. critical period models; accumulation of risk models) which posits that health at a given point in time reflects event and environment exposure across the life course (see Kuh et al., 2003; Singh-Manoux et al., 2004). Social science methods meanwhile typically stem from the assumption that an individual's 'stock' of health can accumulate or depreciate over time either naturally or in response to inputs into the production of health. Both these approaches embed the idea that health is an evolving product of diverse factors such as diet, lifestyle, environment, social habits and so on - factors which change slowly over time and that interact with, and condition, the individual's response and vulnerability to shocks, whether those be in the form of earthquakes, epidemics or socio-economic change.

SKM reject these ideas, instead arguing that there is somehow a structural 'health break' with the past that occurred in 1989, 1990, 1991, 1992 or 1993 (depending on the specific country) and that stocks of health at that point in time were no indicator of what was to follow. They cite the work of Cornia and Paniccia (2000) in support of this approach. In fact, Cornia and Paniccia do not test this thesis. Instead, they show that short-term effects matter - something quite different, and on which we are all in agreement. The crucial conceptual difference then is this: SKM believe that the short-term mortality fluctuations should be viewed in isolation, whereas I argue that they should be understood within the context of an evolving process of health production (the 'persistence hypothesis').

\section{Methodological challenges}

Looking beyond their misleading claims - to have addressed endogeneity by including explanatory variables and; that their specification is derived from theory - the main area of methodological dispute lies in the treatment of serial correlation. Statistically, the conceptual view on 'persistence' determines the preferred approach to serial correlation in the data. My methodological argument is that all of SKM's main findings are statistically questionable (given the nature of the data) and conceptually questionable (given the nature of the data generating process - i.e. persistence).

Unfortunately SKM confirm their conceptual and statistical confusion. Specifically, their discussion implies that I have 'corrected' for serial correlation while they have not, whereas in fact the opposite is true. Their original preferred estimate explicitly 'corrects' for serial correlation by adjusting the standard errors in the presence of an unexplained AR(1) process. If, as it now seems, they prefer to emphasise their fixed effects results, with clustered standard errors (CSE) then their claims are built on no less shaky ground. Kézdi (2004) shows that where the number of clusters is less than 50, inference using CSE may be incorrect more often than without adjustment.

In any event, my approach is quite different. I argue that the observed serial correlation is a product of persistence in the data and an important part of the process which generates the observed data. It is therefore not the standard errors that need adjusting; rather it is the entire model and its coefficients that are wrong. Their confusion is evident: thinking that they are 
criticising my approach, they refer to a variety of literature that counsels against serial correlation correction, culminating with their quoting Mizon's (1995, p.267) warning that statisticians offer "a simple message to autocorrelation correctors: Don't". Quite, but it is their approach which this literature cautions against, not mine.

A necessary implication of the 'persistence' argument is that estimates should be carried out through some dynamic approach and I argue that it is plausible to use the system GMM estimator. The latter is, of course, no panacea, a point made in my article. The mortality data series are almost certainly non-stationary (as suggested by Figure 2 in my paper and the very high $\mathrm{R}^{2}$ statistics that SKM obtain in their estimates) and yet this data series is too short to embrace meaningful time-series approaches. Roodman (2009) carefully catalogues the appropriate choices for establishing the robustness of GMM results. SKM list 7 such choices that they claim I have failed to explain. In fact, my text explains 5 of these choices, as well as other more important steps (e.g. regarding the number of instruments) that Roodman suggests. I did omit to make clear my use of orthogonal deviations or the restriction of the instruments to the equation in levels. However, I do say that the results I find are robust across specifications and I can confirm that they hold with or without orthogonal deviations as well as when instruments are used for both the first-difference and levels equations. SKM's claim that my "constellation of choices attenuates (their) findings to nonsignificance" is therefore simply not correct (Stuckler et al., IN THIS ISSUE). The different estimates serve purely as robustness checks. Ironically, when it comes to presenting their own Table 2 estimates they fail to provide information on any of the choices they make, despite correctly identifying this as best practice with respect to my work.

\section{Russia-Belarus comparison}

SKM go on to discuss a comparison of Russia (a mass privatiser) and Belarus (not a mass privatiser) by drawing, oddly, on different data (which they misreport here as referring to working age males), from a different data source and for an extended time period.

Nevertheless, the Russia-Belarus comparison is interesting because it is clear that mortality fluctuations in Russia are more extreme than in Belarus. SKM's unusual decision to begin their Figure 2A in 1987, the local minimum for adult mortality in the USSR, is visible in comparison with a more complete figure, tracking the data series back to 1980 (Figure 1). It demonstrates that just as mortality rose more sharply in the early 1990s in Russia, it also declined more steeply during the Gorbachev period, and rose again more sharply in the late 1990s, following the financial crisis. These differences pre- and post-date mass privatisation by a decade. By way of counter anecdote, comparing the experiences of Russia and Georgia (two mass privatisers) and Belarus and Estonia (two non-mass-privatisers) further muddies the SKM story. Within each pairing (Figure 2) male mortality diverges through the 1990s.

The countries of this region are complex and diverse, and the causal factors at work are impossible to disentangle with crude aggregated data and blunt dummy variables situated within a historical vacuum. A more likely explanation, consistent with persistence, emerges in important recent work (Bhattacharya et al., 2011) showing that regions in which alcohol consumption and mortality had fallen most steeply during the Gorbachev campaign had also experienced the largest transition era increases and that mortality patterns across the region were "commensurate with campaign exposure". The authors conclude that "Russia's transition to capitalism and democracy was not as lethal as commonly suggested". 


\section{Data Torture}

Finally, in Table 1, SKM challenge the results that I have actually presented. Their column (1) result reports a lagged term that is both insignificant and falls outside of the downwardly biased lower bound (0.30) provided by a fixed effects equivalent of their estimate. This suggests that the lagged levels of the regressors are poor instruments for the first difference regressors and that, most likely, by reducing the sample size to below 150 and $n$ to 15 the power of these regressions is low. However, if - as they claim - SKM believe this to be a plausible dynamic specification in support of their findings, then they should also report the same specification using their average privatisation variable. Had they done so, we would see that: the lagged term is significant and within the acceptable range; the various specification and identification tests are satisfied; other variables (war, higher education and urbanisation) become significant; but crucially, average privatisation is insignificant. Furthermore, with respect to their columns 1 and 2, SKM assert that other "controls, such as war and income, take on plausible associations, significantly negative and positive, respectively, as in our original models." This is not correct as, in fact, GDP is insignificant in (1) and positive and significant in (2) - precisely the reverse of their original findings.

The remainder of Table 1 is less valid still, as confirmed in columns (2) - (6) by the Hansen test statistics of 1.00 - a sure indication that the estimates are heavily over-instrumented and in no way replicate what I have done, let alone reflect a sequential introduction of the "manipulations used by Gerry". Indeed, if they repeat their Table 1 exercise with an acceptable number of instruments commensurate with valid statistical tests, their argument unravels still further, since the mass privatisation (or the average privatisation) coefficients are never significantly different from zero (their claim that I misreport a diagnostic test is also incorrect: the correct Hansen test statistic is, as reported, 0.13).

Finally, I can only comment briefly on their Table 2 results since they disregard their own advice and that of Roodman in presenting their results. The number of countries has increased by 2 compared to their original dataset and there is no indication of the choices they have made in specifying the model, even down to the number of instruments. All my attempts to recreate their findings result, unsurprisingly given their inclusion of multiple lags, in failed $\operatorname{AR}(2)$ tests which invalidate their results.

\section{Conclusion}

Dynamic system GMM is not a panacea. It does, however, represent an approach that is consistent with the underlying data generating process being discussed here and to that extent one would naturally want to find results consistent with those found using other techniques. This is particularly the case for non-structural estimates, covering very small samples, over short-time periods and with aggregate data used to proxy for processes that take place at an individual level. SKM have tried to investigate a bold hypothesis using just such data and have objected to those that seek to interrogate their findings.

Like others, I am not persuaded by their original claim and still less so by the validity and appropriateness of their attacks on those who question them. In their latest response they have proposed a dynamic specification that fails the most rudimentary of procedural statistical checks and that disregards my related points about endogeneity. They have made claims about methodology and findings that are demonstrably incorrect, have misrepresented and/or misused the findings of important literature in this field and continue to argue that 
'persistence' is biologically implausible. The causal pathways between socio-economic upheaval and ill-health are far more complex and inter-related than SKM propose by headlining the role of rapid mass privatisation. Those who observe this should not be accused of data torture, statistical obscurantism or of pursuing an ideological brief. On the contrary, this is a seam of scientific research searching to better understand the continued catastrophic patterns of mortality and morbidity that characterise parts of this region of the world. A part of that endeavour involves legitimately questioning findings that appear to have limited support in the data or in the field.

\section{References}

Bhattacharya, J., Gathmann, C. \& Miller, G. (2011) The Gorbachev Anti-Alcohol Campaign and Russia's Mortality Crisis. Unpublished manuscript.

Brainerd, E. (1998). Market reform and mortality in transition economies. World Development, 26, 2013-2027.

Brainerd, E. (2001). Life and death in Eastern Europe: Economic reform and mortality in the former Soviet Union: A study of the suicide epidemic in the 1990s. European Economic Review, 45, 1007-1019.

Cornia, G.A., \& Paniccia, R. (2000). The mortality crisis in transitional economies: Oxford University Press.

Gerry, C., Mickiewicz, T, Nikoloski, Z (2010). Did mass privatization really increase postcommunist mortality? The Lancet, 375, 371.

Gerry, C, The journals are full of great studies but can we believe the statistics? Revisiting the mass privatisation - Mortality debate (IN THIS ISSUE)

Kézdi, G. (2004) Robust Standard Error Estimation in Fixed-Effects Panel Models. Hungarian Statistical Review. Special English Volume 9, pp. 95-116.

Kuh, D., Ben-Shlomo, Y., Lynch, J., Hallqvist, J. \& Power C. (2003) Life course epidemiology. Journal of Epidemiology and Community Health. 57(10):778-83.

Mizon, G. (1995). A simple message for autocorrelation correctors: Don't. Journal of Econometrics, 69.

Popper, KR. (2005) The Logic of Scientific Discovery. London: Routeledge, Taylor and Francis e-library. (First published in German 1934; in English, 1959).

Roodman, D. (2009) How to do xtabond2: An introduction to difference and system GMM in Stata. Stata Journal. Vol. 9(1):86-136

Saburova, L., Keenan, K, Leon, DA, Elbourne, D (2011). Alcohol and fatal life trajectories in Russia: understanding narrative accounts of premature male death in the family. $B M C$ Public Health, 11, 481.

Stuckler, D., King, L., McKee, M (2009). Mass privatisation and the post-communist mortality crisis. The Lancet, 373, 399-407.

Stuckler, D., King, L., McKee The disappearing health effects of rapid privatisation: a case of statistical obscurantism? (IN THIS ISSUE)

Singh-Manoux, A., Ferrie, JE., Chandola, T. \& Marmot, M. (2004) Socioeconomic trajectories across the life course and health outcomes in midlife: evidence for the accumulation hypothesis? Int. J. Epidemiol. 33(5):1072-79.

Figure 1: Mortality Patterns - Belarus vs. Russia 


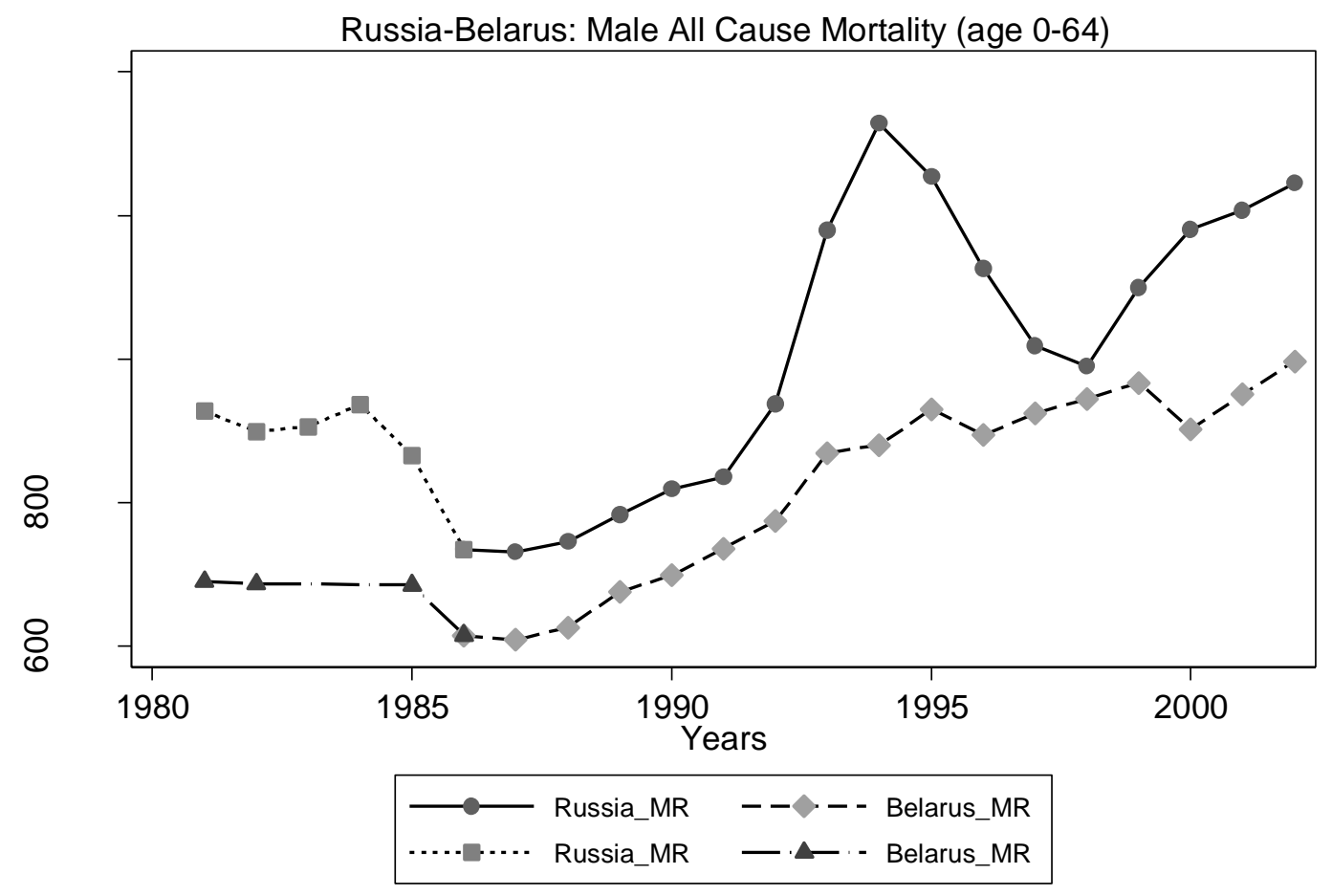

Source: WHO European Health for All Database (2011)

Figure 2: Mortality patterns: privatisers (Russia/Georgia) vs non-privatisers (Estonia/Belarus)

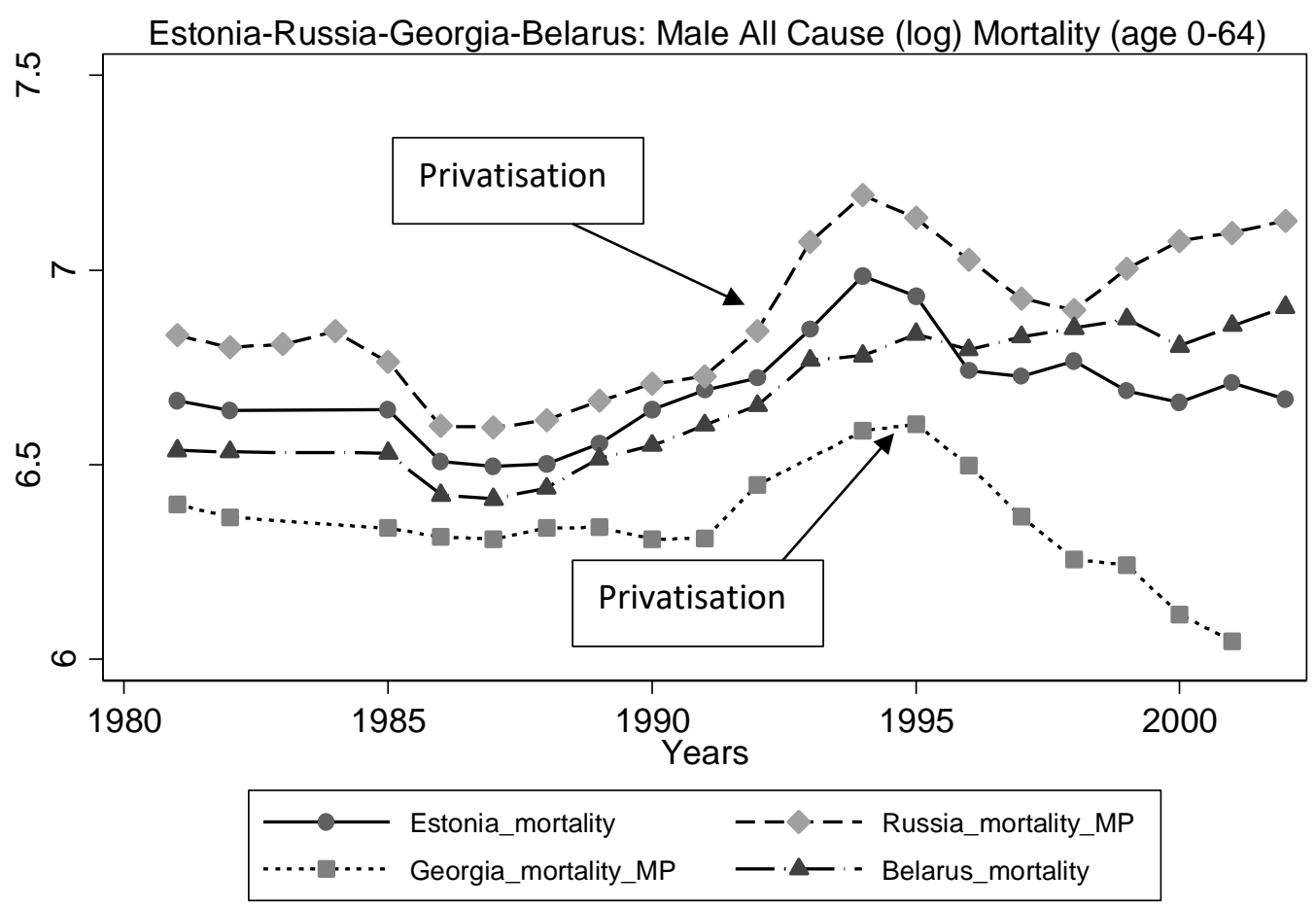

Source: WHO European Health for All Database (2011)

Acknowledgements 
I am particularly grateful for the comments of Elizabeth Brainerd, Christopher Davis, JJ Gurga, Carmen Li, Svetlana Makarova, Tomasz Mickiewicz, Judith Shapiro, Charles Walker and participants at conferences and seminars in London, Moscow, Tartu, Tbilisi and Vienna. 